\title{
Effectiveness and Mechanism of Preoperative Lugol Solution for Reducing Thyroid Blood Flow in Patients with Euthyroid Graves' Disease
}

\author{
Ashwini Reddy $^{1} \cdot$ Gyan Chand $^{1} \cdot$ Sabaretnam Mayilvaganan $^{1}$
}

Published online: 25 February 2016

(C) Société Internationale de Chirurgie 2016

To the Editor,

We read with interest the article "Effectiveness and Mechanism of Preoperative Lugol Solution for Reducing Thyroid Blood Flow in Patients with Euthyroid Graves' Disease" authored by Shih-Ming Huang et al. [1]. This prospective study emphasised the role and mechanism of lugol iodine in reducing vascularity of thyroid gland in euthyroid Graves' disease which resulted in reducing the vascularity of the thyroid gland pre-operatively and thereby enabling safe thyroidectomy, as highly vascular glands with high blood flow are associated with increased operative blood loss and increased incidence of complications [2]. We also congratulate the authors for incorporating the markers VEGF and IL-16 and thereby making it clear with evidence the efficacy of lugol's iodine. We have few queries which may interest future readers.

Did the severity of Graves' disease in terms of percentage of patients with ophthalmopathy, mean doses of antithyroid drugs required, mean thyroid gland weight affect the reduction in vascularity? Did the authors perform subgroup analysis and did they find whether only a subset require lugol's iodine? The study has shown that pre-operative treatment with lugol solution reduces blood flow to thyroid, whether it translated into significant difference in intraoperative blood loss between the lugol-administered and lugol not-administered group? Further in the study by Erbil et al., there was a significant reduction in intraoperative blood loss between the two groups [3]. It would be highly appreciative if the authors could mention if there were any complications or untoward incidents due to lugol iodine administration.

\section{References}

1. Huang SM, Liao WT, Lin CF, Sun HS, Chow NH (2015) Effectiveness and mechanism of preoperative lugol solution for reducing thyroid blood flow in patients with euthyroid Graves' disease. World J Surg. doi:10.1007/s00268-015-3298-8

2. Huang SM, Chow NH, Lee HL, Wu TJ (2003) The value of color flow Doppler ultrasonography of the superior thyroid artery in the surgical management of Graves disease. Arch Surg 138(2):146-151 discussion 151

3. Erbil Y, Ozluk Y, Giriş M, Salmaslioglu A, Issever H, Barbaros U, Kapran Y, Ozarmağan S, Tezelman S (2007) Effect of lugol solution on thyroid gland blood flow and microvessel density in the patients with Graves' disease. J Clin Endocrinol Metab 92(6):2182-2189
Sabaretnam Mayilvaganan

drretnam@gmail.com

1 Department of Endocrine and Breast Surgery, Sanjay Gandhi Postgraduate Institute of Medical Sciences, Lucknow, India 